\title{
Condicionantes institucionais e políticos e poder de barganha nas negociações internacionais sobre agricultura: o caso da União Européia
}

\author{
Institutional and political constraints and bargain power in \\ agriculture international negotiations: the case of EU
}

MARIA IZABEL VALLADÃO DE CARVALHO*

Rev. Bras. Polit. Int. 49 (2): 99-118 [2006]

\section{Introdução}

Em outubro de 2005, as vésperas da Conferência Ministerial da OMC em Hong Kong (12-18 de dezembro), o ministro de Comércio da França, Christine Lagarde, acusou Peter Mandelson de estar excedendo a sua autoridade negociadora com as propostas de redução dos subsídios agrícolas e cortes nas tarifas de importação na área agrícola ${ }^{1}$. Em seguida, a França, com o apoio de 12 países, conseguiu que a Inglaterra, que exercia a presidência da União Européia - UE, convocasse uma reunião de emergência dos ministros das Relações Exteriores dos Estados-membro para discutir suas preocupações relativas ao comportamento do Comissário de Comércio Exterior. $\mathrm{Na}$ mesma semana, 13 ministros de Agricultura da UE, sob a liderança da França, enviaram carta para Peter Mandelson requerendo o direito de serem consultados a respeito de possíveis concessões na área agrícola.

Apesar da reunião de emergência ocorrida em Luxemburgo em 18 de outubro não ter resultado na imposição de limites à atuação de Peter Mandelson, o que era requerido pela França, os ministros concordaram em acompanhar mais de perto as negociações.

\footnotetext{
* Professora do Instituto de Relações Internacionais da Universidade de Brasília - UnB, Doutora em Ciência Política pela Universidade de São Paulo e Pós-Doutorado em Política Internacional no Centre for International Studies da London School of Economics and Political Science (mabel@unb.br).

${ }^{1}$ Este artigo foi apresentado no $5^{\circ}$ Encontro da Associação Brasileira de Ciência Política, em Belo Horizonte, 26-29 de julho de 2006. A pesquisa que embasou o trabalho teve apoio da Capes por meio de bolsa de Estágio Pós-Doutoral no Centre for International Studies da London School of Economics and Political Science entre 2003 e 2004.
} 
Em 27 de outubro, às vésperas da UE apresentar uma nova proposta, o presidente da França, Jacques Chirac declarou que o seu país bloquearia a aprovação de acordos que colocassem em risco a Política Agrícola Comum (PAC), aprovada em 26 de junho de 2003 pelos ministros da Agricultura com vigência até $2013 .^{2}$

Em decorrência dessas várias pressões, a Comunidade Européia que parecia caminhar para aumentar as suas ofertas na agricultura, principalmente na área de cortes nas tarifas de importação, recuou. Em 28 de outubro, ela apresentou uma proposta modesta - $46 \%$ em média e $60 \%$ em sua tarifa mais alta. Além disso, passou a declarar que não tinha mais nada o que oferecer, e que, de agora em diante, as negociações deveriam se concentrar nas ofertas dos países em desenvolvimento para abertura de seus mercados para produtos industriais e serviços.

Por que em uma negociação que envolve a política supranacional por excelência da UE - a sua política comercial externa - alguns países como a França, são capazes de ter uma ingerência tão decisiva no processo negociador? Quais as conseqüências desses fatos para o desenrolar das negociações multilaterais de comércio? Como tais Estados afetam o desempenho dos adversários da UE e a sua faculdade de influenciarem o desfecho das transações? Este trabalho procura responder a essas questôes investigando dois problemas: o papel que normas formais e informais exercem no processo de tomada de decisão da política comercial externa da UE e a influência da PAC nas negociaçôes multilaterais sobre agricultura.

Argumenta-se, primeiro, que as normas do processo de tomada de decisão podem proporcionar aos Estados-membro um poder de veto sobre os acordos em discussão. Em vista disso, em áreas econômicas sensíveis, aqueles que têm uma posição mais próxima do status quo adquirem influência decisiva no desenvolvimento das negociaçôes e em seus resultados finais. Utiliza-se aqui a conceituação proposta por Tsebelis (2002:2) para identificar atores com poder de veto a saber, atores cuja concordância é necessária para mudar o status quo no âmbito legislativo.

Tendo em vista os constrangimentos colocados pelas regras institucionais, o poder de barganha da UE nas negociações multilaterais é aumentado, restringindo a margem de manobra de seus opositores e dificultando ações desses atores para avançar seus interesses. Esta situação é agravada no caso de uma negociação multilateral de comércio como o da Rodada Doha, onde a questão central é a redução dos subsídios agrícolas os quais são regulados por

2 "US and EU pressed on Doha Concessions", Financial Times, 11.10.2005. http://www.FT.com. "Emergency meeting called on Doha offer", id.ibid., 13.10.2005; "EU approves farm tariff cuts proposal", id.ibid., 18.10.2005; "Chirac will block Doha before cuts in farm aid ", id.ibid., 28/10/2005; "EU juggles in bid to revive trade talks", id.ibid., 28.10.2005. Visitada em 30/10/2005. "Brasil pressiona ricos por limites", O Estado de São Paulo, 20 de outubro de 2005, p. B8. 
uma política agrícola que beneficia mais alguns Estados do que outros e que adquiriu um respaldo na opinião pública da UE para além de seus benefícios econômicos.

A PAC da União Européia é, assim, um elemento que vem se somar aos constrangimentos institucionais para elevar o poder de barganha da UE. Além disso, as regras que regulamentam as decisóes no âmbito da PAC contribuem para que suas reformas sejam incrementais ou parciais, dificultando mudanças substantivas e aproximando-as da manutenção do status quo.

Na primeira parte do artigo, as instituiçóes que regulam o processo decisório da política comercial externa da UE são analisadas com o fito de demonstrar os limites e oportunidades que elas colocam para a influência dos Estados-membro nas negociaçóes dos acordos multilaterais de comércio. Busca-se mostrar que as tensões entre os interesses dos Estados-membro e os da Comunidade Européia perpassam várias áreas de questōes, sendo a agricultura o exemplo mais flagrante. Em seguida, é feito um histórico da formação e evolução da PAC para destacar a dimensão gradual de suas mudanças. A terceira seção investiga o comportamento da UE nas Rodadas Uruguai e Doha do Desenvolvimento, incluindo a VI Ministerial em Hong Kong (12-14 de dezembro de 2005) e indica-se que os seus resultados aproximam-se mais das posiçôes defendidas pela UE do que a de seus adversários como os Estados Unidos (EUA), o Grupo de Cairns, o G20, bem como o Brasil. A conclusão contextualiza teoricamente as questôes colocadas no artigo e discute alguns aspectos do impacto dos condicionamentos institucionais e políticos sobre a atuação da UE e de seus contendedores nas negociaçôes multilaterais de comércio.

\section{Regras institucionais e áreas econômicas sensíveis: a tensão entre os interesses dos Estados e os da Comunidade Européia}

São três os modos de relacionamento da União Européia com o ambiente global: o primeiro se refere à política externa da Comunidade Européia $(\mathrm{CE})^{3}$ e abrange comércio e desenvolvimento; o segundo consiste na Política Exterior Comum e de Segurança; e o terceiro inclui a dimensão externa de Justiça e Assuntos Internos. Estes três níveis ou pilares apresentam instituições e regras de tomada de decisão diferentes.

Enquanto o primeiro pilar é o nível comunitário por excelência, com uma clara dimensão supranacional, onde a Comissão Européia - o órgão executivo da União Européia - possui um papel decisório significativo, as ações dos Estados dominam a deliberação dos outros pilares. A operação das relações externas da

${ }^{3}$ A Comunidade Européia é a designação oficial do primeiro pilar da União Européia, encarregado da política econômica e comercial externa. 
UE nestes dois últimos níveis ocorre, assim, e principalmente por meio da interação entre os governos dos Estados-membro (Smith, 2003; White. 2001).

A competência exclusiva para negociar e concluir acordos bilaterais, regionais e multilaterais de comércio foi concedida pelos Estados-membro à $\mathrm{CE}$ desde a sua instituição. Esta autorização se originou nas bases do próprio processo de integração: a instituição de um mercado comum fundamentado em uma união aduaneira. Neste contexto, as ligações com terceiros países em suas trocas comerciais só poderiam se efetivar com o estabelecimento de tarifas consensualmente acordadas e que valessem para todo o conjunto de países que compusessem a CE. Além disso, o poder de influência da CE nas negociações internacionais de comércio está diretamente relacionada a sua capacidade em atuar de forma integrada, isto é agir com "uma voz única" (Meunier, 2000).

A autoridade para transacionar e concluir acordos é da Comissão Européia (Comissão). Cabe, no entanto, ao Conselho de Assuntos Gerais e Negócios Exteriores (CAG) composto pelos ministros das Relaçôes Exteriores dos Estadosmembro, autorizar o início do processo negociador e aprovar ou rejeitar o acordo concluído.

Essas decisões, porém, devem ser adotadas segundo a regra de votação por maioria qualificada, ${ }^{4}$ a qual eliminaria a capacidade de influência dos interesses de cada estado tomado individualmente. A opção pela regra da maioria qualificada para as negociações comerciais externas expressou a vontade dos membros constituintes da UE de que a política comercial fosse efetivamente definida ao nível supranacional, expressando, por conseguinte, um interesse coletivo para além dos interesses particulares de seus governos. Já no segundo e terceiro pilares - a Política Exterior Comum e de Segurança e a dimensão externa de Justiça e Assuntos Internos - tem sido mais difícil para os Estados, tendo em vista os tipos de política compreendidos nesses níveis, abdicarem de sua autonomia em influenciar diretamente a tomada de decisão. Em conseqüência, nesses dois casos, a regra de votação dominante é a unanimidade.

Porém, como se verá a seguir, a evolução da participação da CE nas negociações multilaterais de comércio a partir da Rodada Uruguai exprimiu uma tensão entre, por um lado, a necessidade dos Estados em atuar no nível comunitário para conduzir a política comercial externa; e, por outro lado, seus interesses em manter controle sobre áreas que afetavam de forma mais intensa as suas preferências. Em conseqüência, a regra da maioria qualificada para as deliberações no âmbito das negociações multilaterais de comércio passou a sofrer restrições, bem como a decisão informal do uso da regra da unanimidade se consolidou.

\footnotetext{
${ }^{4} \mathrm{O}$ sistema de votação qualificada atribui para cada Estado um número de votos aproximadamente proporcional ao seu tamanho. Uma maioria de votos, atualmente $71 \%$,é necessária para que uma decisão seja aprovada no Conselho da União Européia.
} 
Dois fatores devem ser considerados para explicar as mudanças nas regras do processo decisório: primeiro, a nova conformação do ambiente econômico global e o seu impacto na instituição da agenda do comércio multilateral nos anos 80 e, segundo, a inclusão da agricultura nas negociaçōes da Rodada Uruguai.

$\mathrm{Na}$ década de 1980, novas áreas de atividades econômicas tornaram-se relevantes no contexto internacional tais como: serviços, investimento e questōes de direito de propriedade intelectual relacionadas ao comércio. A Rodada Uruguai incluiu-as em sua agenda de negociação - os chamados de "novos temas" - com muita resistência dos países em desenvolvimento, que não tinham naquele momento, vantagens comparativas nesses campos (Mello, 1992; Abreu, 1997). Contudo, sob o ponto de vista do processo decisório da política comercial externa da UE tratava-se de determinar quem teria a competência para negociar e concluir acordos "nos novos temas": a Comissão Européia , os Estados-membro ou ambos?

Como os efeitos do meio internacional no comportamento dos Estados não são diretos, mas mediados pelo ambiente doméstico, diferenças em competitividade entre os membros da UE levaram-nos a resistir em delegar autoridade para que a Comissão negociasse e concluísse acordos naquelas áreas. Dessa maneira, durante a Rodada Uruguai, na perspectiva dos Estados-membro os "novos temas" deveriam ser negociados segundo as regras da competência nacional ou, no mínimo da competência mista, onde a autoridade negociadora é compartilhada entre os Estados e a Comunidade (Woolcock, 2000:376). Uma estreita vigilância dos Estados-membro sobre o comportamento da Comissão e o pacto de que tanto a Comissão como os Estados-membro assinariam o acordo final contribuíram para diminuir as tensôes entre estes dois atores durante o processo negociador. (id.ibid).

A criação da Organização Mundial do Comércio (OMC) intensificou outra vez o debate. A proposta da Comissão de que a CE e os Estados-membro deveriam ser membros integrais da OMC não foi suficiente, pois quem deveria ser o ator negociador no novo organismo diante de uma agenda do comércio internacional mais complexa e reguladora das políticas domésticas?

Retornou assim à baila a controvérsia a respeito de quem teria autoridade para negociar os "novos temas" no âmbito da OMC. A decisão sobre esta questão ocorreu em um contexto de desconfiança em relação ao comportamento da Comissão, já que para alguns Estados, principalmente a França, ela tinha excedido a sua autoridade negociadora nas transaçōes do Acordo Agrícola de Blair House (Meunier e Nicolaidis, 1999; 484). A decisão foi levada à Corte de Justiça Européia que deu um parecer favorável aos Estados-membro, que não queriam renunciar à soberania decisória nos novos temas. Segundo a Corte, a Comunidade teria competência somente para concluir acordos multilaterais em mercadorias. Os acordos em serviços (Gats) e propriedade intelectual 
(Trip's), por sua vez, deveriam ser concluídos pela Comunidade e pelos Estadosmembro (id.ibid.: 488)

$\mathrm{Na}$ revisão do Tratado de Maastricht a partir de 95 e que resultou no Tratado de Amsterdã em 99 tentou-se estender a competência da Comunidade à negociação dos "novos temas". Porém, o que se alcançou foi, apenas, que novos acordos em propriedade intelectual e serviços poderiam ser negociados pela Comissão a partir de uma autorização do CAG tomada sob regra da unanimidade. Em consequiência, as decisões naquelas duas áreas foram mantidas sob a influência individual dos Estados, lhes proporcionando um poder de veto sobre elas.

A ampliação parcial da competência decisória da Comunidade em relação a serviços e propriedade intelectual foi estabelecida no Tratado de Nice (2001). Mas ela relacionou-se a setores específicos de serviços; e, no caso de propriedade intelectual a esferas em que regras internas já tivessem sido instituídas pelos Estados-membro. Em conseqüência, negociações abrangentes dos "novos temas", incluindo investimentos, serviços e propriedade intelectual devem ser decididas por acordos mistos, isto é acordos em que a competência decisória é compartilhada entre a Comunidade e os Estados-membro, o que possibilita a esses “(...) reterem um veto por meio do voto unânime no Conselho (CAG) e por meio de ratificação pelos seus próprios parlamentos" (Meunier e Nicolaïdis, 1999: 480).

Em relação à agricultura é importante tecer, inicialmente, algumas considerações relativas às razões pelas quais este setor econômico não esteve integrado às regras do Acordo Geral de Tarifas e Comércio (Gatt) desde o sua criação em 1947 e como isso colaborou para solidificar a PAC ao longo do tempo. Em seguida, serão discutidas as regras de tomada de decisão na negociação de acordos multilaterais em agricultura.

Apesar de defenderem a liberalização do comércio mundial no final da Segunda Guerra Mundial, os EUA não tiveram a mesma postura quando se tratou de agricultura, já que a legislação comercial americana protegia este setor das flutuações no mercado internacional (Goldstein,1993). Em vista disso, os negociadores americanos lutaram e conseguiram que fosse permitido o uso de restrições quantitativas no caso da agricultura (artigo 11 do Acordo Gatt) e que "exportações agrícolas eram uma exceção a qualquer compromisso contrário a subsídios á exportação" (Id. Ibid.: 218).

Além do mais, em 54 os EUA obtiveram do Gatt uma exceção (waiver) para a sua política agrícola que permitiu o uso de restriçôes quantitativas às importações de produtos agrícolas mesmo na ausência de um programa doméstico direcionado a reduzir a produção dos mesmos como previsto no artigo 11 citado. A PAC, instituída em janeiro de 62, beneficiou-se claramente da existência dessas regras que, não só possibilitaram a sua criação, mas também que ela se consolidasse ao longo do tempo (Id.Ibid.). 
Estando profundamente incrustada no modo como a produção agrícola funcionava na $U^{5}$, e dentro das normas do Gatt, a mudança das regras da PAC em uma direção liberalizante, ainda que de modo incremental, só veio a ocorrer durante a Rodada Uruguai. A reforma resultou, por um lado, de séria crise nos recursos da PAC que incidiu negativamente sobre o orçamento da UE, decorrente dos problemas de superprodução nos anos 70 e 80 ; e, por outro lado, da pressão internacional, agora dos EUA, somados ao Grupo de Cairns e com a atuação expressiva do Brasil (Mello, 1992; Abreu, 1997; Patterson, 1997),

A agricultura é, por conseguinte, uma área de grande sensibilidade para a UE, na medida em que ela afeta um conjunto de interesses solidificados no ambiente doméstico de seus Estados-membro. Em conseqüência, o grau de flexibilidade da Comissão para negociar acordos nessa área é restrito. Segundo Woolcock, "os mandatos são usualmente rigorosos em questôes sensíveis, como agricultura” (2000: 301).

Na preparação do mandato negociador para a Rodada Doha, por exemplo, o presidente da Uniāo Européia determinou que o mandado para a agricultura fosse submetido ao Conselho de Agricultura, antes de ser enviado ao CAG ${ }^{6}$, como forma de eliminar qualquer tipo de divergência entre os Estados-membro nessa área.

Cabe, ainda, destacar que nas discussões de acordos de comércio internacional envolvendo a agricultura, o Comissário para a Agricultura participa ao lado do negociador formal da CE, ou seja, o Comissário para Comércio Exterior. Esta é uma situação que não se repete em outras esferas negociadoras e expressa a intensidade dos efeitos que decisóes neste setor têm sobre as preferências dos Estados-membro.

Em transaçóes abrangentes como as rodadas do Gatt e da OMC a regra formal da votação por maioria qualificada para a conclusão do acordo vem sendo substituída pelo consenso (Woolcock, 2000: 384). Em conseqüência, "a Comissão tem espaço limitado para manobra, porque ela não pode apelar para uma maioria qualificada de governos para derrotar interesses minoritários. Governos-membro que se opõem a elementos de um pacote proposto, tais como liberalização em agricultura, podem ser efetivamente capazes de exercer um veto no resultado" (Id.bid.; 385).

Esse mesmo raciocínio pode ser aplicado à decisão por votação de maioria qualificada para a aprovação do mandato no CAG, já que na prática os Estadosmembro procuram chegar a um texto comum na fase inicial do processo negociador (Meunier e Nicolaïdis, 1999:480).

\footnotetext{
${ }^{5} \mathrm{Na}$ seção seguinte do artigo explora-se de modo mais detalhado as razóes pelas quais a PAC está intensamente vinculada a produção agrícola na UE, apesar dos problemas de ineficiência econômica.

${ }^{6}$ Entrevista com embaixador João Pacheco, chefe da Delegação da União Européia no Brasil, Brasília, 6 de dezembro de 2005.
} 
Desta maneira, os Países-membro, por meio de regras informais e formais estão continuamente influenciando o processo decisório da UE nas transações multilaterais de comércio. Por conseguinte, apesar de a política comercial externa ser a política comunitária por excelência da UE - aquela que expressaria, mais do que qualquer outro nível de atuação exterior da UE o interesse coletivo de seus membros - ela sofre a influência decisiva dos Estados-membro cujas preferências aproximam-se do status quo. Isto tolhe a capacidade dos Estados opositores da UE em negociações de comércio internacional de obter concessões significativas em áreas sensíveis, sobretudo em agricultura, que é o objeto de estudo deste artigo.

\section{Consolidação e reforma da Política Agrícola Comum (PAC)}

Esta seção do artigo procura mostrar porque a PAC é um poderoso fator que constrange o comportamento dos opositores da UE nas rodadas multilaterais de comércio, restringindo suas margens de manobra durante o processo negociador. Em primeiro lugar, expõem-se as razões pelas quais a PAC consolidou-se nas instituiçóes da UE e nas sociedades dos Estados-membro a partir de uma análise de seus objetivos e dos mecanismos criados para alcançálos; em segundo lugar, mostra-se como esta consolidação se expressou nas dificuldades para modificá-la, investigando-se as várias reformas que a PAC sofreu a partir dos anos 70 .

A política agrária da UE é regida por um conjunto de normas e princípios consubstanciados na PAC. Instituída em 62, a PAC está profundamente incrustada nos interesses dos agricultores da UE, já que desde o seu início ela mesclou objetivos distributivos e econômicos. Além do mais, para a implementação dessa política formou-se uma ampla rede de instituições burocráticas que vincularam os níveis municipal, nacional e supranacional da instituição européia. Um conjunto de interesses sociais, políticos e burocráticos direcionados para a manutenção daquela política constituiu-se, deste modo, ao longo dos anos e impediram que ela sofresse mudanças significativas.

A PAC surgiu no contexto da construção do estado de bem estar social na Europa no após-guerra. Desse modo, além de ter como um de seus objetivos estimular a produção de alimentos, tornando os países membros auto-suficientes nesta área, a PAC ainda visou proteger a renda dos trabalhadores (Rieger, 2000; Fouilleux, 2003). Somado a isto, destacou-se o seu objetivo político: obter o apoio dos agricultores ao projeto de integração européia - projeto este que abrangeu no seu começo a França, Alemanha, Itália, Holanda, Bélgica e Luxemburgo A combinação de dimensões distributivas e econômicas nessa política agrícola é um dos fatores que explica as dificuldades para a sua modificação, já que ela acabou por se enraizar de forma profunda nos interesses de produtores agrícolas grandes e pequenos. 
Os aspectos distributivos e econômicos estão claramente enunciados no artigo 39 do Tratado de Roma:

1) aumentar a produtividade da agricultura, (...) assegurando o desenvolvimento racional da produção agrícola e a ótima utilização dos fatores de produção, em particular do trabalho; 2) assegurar um padrão de vida justo para a comunidade agrícola e em particular elevando os rendimentos individuais das pessoas empregadas na agricultura; 3) estabilizar os mercados; 4) assegurar a disponibilidade dos suprimentos, e assegurar que os suprimentos cheguem aos consumidores a preços razoáveis (Fouilleux, 2003: 247).

Os princípios que nortearam a implementação da PAC, como a garantia de preço para os produtores e um sistema de reembolso para cobrir a diferença entre o valor da produção interna em relação ao valor exportado, foram, por sua vez, estabelecidos na Conferência de Stresa em 58 e entraram em vigor em 1962. Eles compreenderam a unidade de mercado (um mercado único), a preferência comunitária; e a solidariedade financeira (id.ibid).

$\mathrm{O}$ mercado comum passou a funcionar com um preço assegurado para os produtos agrícolas determinado de forma centralizada pelos funcionários da Comunidade e pelos políticos dos Estados-membro. Se o preço caísse, o que reduziria os ganhos dos produtores e afetaria negativamente a oferta, agências estabelecidas no nível nacional deveriam comprar o excesso da produção (id.ibid.), substituindo dessa forma a "mão invisível do mercado" pela atuação da burocracia estatal. Além disso, para impedir que as instabilidades do mercado internacional prejudicassem o desempenho do mercado interno fixouse de modo centralizado e acordado com os países-membros um preço de entrada para cada produto agrícola importado. Somado a isto incluiu-se "um sistema de "reembolsos" (...) permitindo aos produtores europeus vender seus produtos no mercado externo mundial pelos preços determinados pelo mercado mundial. Esses subsídios cobriam a diferença em custo entre o mundo e os preços europeus mais altos." (Id. Ibid., 248). Os produtores agrícolas foram, assim, incentivados neste sistema a produzir cada vez mais, pois quanto mais eles produziam mais eles recebiam dos governos dos Estados-membro. Por último, os recursos financeiros necessários para administrar e implementar a PAC resultaram da criação de um fundo comum, com a contribuição de todos os Estados-membro, o European Agricultural Guindance and Guarantee Fund (EAGGF). No início de funcionamento da PAC, os recursos da EAGGF alcançaram a quase totalidade do orçamento da CEE, decaindo de $65,1 \% \mathrm{em}$ 1986 para $53,8 \%$ em 2000.

Entretanto, com o passar dos anos, a PAC começou a apresentar problemas que ameaçaram a sua sobrevivência. Os incentivos para os agricultores produzirem independentemente dos sinais do mercado colaboraram para as crises de superprodução dos anos 70 e 80 . Estas por sua vez elevaram os custos 
daquela política com tal intensidade que acabaram por colocar em risco o próprio orçamento da UE. Dessa maneira, surgiram pressôes internas para reforma-la (Fouilleux, 2003).

Aliadas a elas destacaram-se, ainda, como fatores relevantes para as mudanças da PAC, as pressōes que se desenvolveram no ambiente internacional durante as Rodadas Uruguai (Patterson, 1997) e Doha, e que contribuíram para desencadear as reformas de 1992 e a de Meio Período de 2003.

Contudo, um exame das várias reformas da PAC indica que medidas mais significativas, ainda que propostas pela Comissão, são limitadas pela atuação dos Estados-membro mais protecionistas. Desta forma, ainda que não se possa dizer que plus ça change, plus c'est la même chose, vale destacar que os efeitos das mudanças aprovadas são reduzidos e que o seu avanço no sentido de criar um ambiente mais competitivo para a agricultura européia é lento. Sob o ponto de vista do impacto desta situação no processo negociador, ressalta-se o limitado espaço de manobra que este contexto propicia aos oponentes da UE no âmbito negociador.

As primeiras modificações dos anos 70 e 80 na PAC foram tópicas e visaram combater os problemas da superprodução por meio do estabelecimento de reduções quantitativas da produção. Além disso, "o princípio de preços garantidos para os produtos agrícolas permaneceu o elemento central da PAC, e não foi tocado pela reforma" (Fouilleux 2003:249).

Com a reforma de 92, pela primeira vez, os problemas de superprodução passaram a ser enfocados a partir de cortes nos preços. Mas a aplicação deste instrumento foi bastante restrita. Não obstante esta limitação, enfrentou-se, ainda que de forma tímida, o princípio do preço garantido. Além disso, objetivando manter os rendimentos dos produtores agrícolas, uma modalidade de apoio a renda foi criada - o sistema de pagamentos diretos - a qual veio se tornar parte integrante da PAC nas reformas seguintes. Por este sistema, os agricultores passariam a receber recursos diretamente para compensar as perdas decorrentes dos cortes efetuados nos preços (id.ibid).

A perspectiva de um alargamento futuro da UE, com países do centro e leste da Europa levou a Comissão Européia em 1997, a propor uma nova reforma da PAC consubstanciada no documento Agenda 2000: For a Stronger and Wider Union. Já estão presentes neste documento as preocupações em vincular a atividade agrícola com aspectos não-comerciais como a proteção ao meio ambiente e medidas de desenvolvimento rural. (Landau, 2001:915-916; Fouilleux, 2003: 257).

No Conselho Europeu ${ }^{7}$ em Berlim, em março de 1999, que debateu e aprovou a Agenda 2000, as propostas da Comissão que envolveram mudanças

7 O Conselho Europeu é a autoridade política da União Européia reunindo os chefes de Estado e de Governo e o presidente da Comissão Européia. 
mais estruturais da PAC como "a dissociação do apoio da renda da produção de maneira mais séria, introduzindo tetos e (alguma) redução escalonada nos pagamentos dos rendimentos, e tornando os membros dos governos responsáveis por algum co-financiamento dos pagamentos diretos" não foram aceitas e a deliberação a respeito dessas questôes foi adiada para 2002-2003. (Rieger, 2000: 203).

Incorporaram-se certas modificaçôes à PAC, as quais abrangeram: "alguma redução de preço compensado por pagamentos diretos dos rendimentos, pagamentos diretos dos rendimentos em relação com medidas de proteção do meio-ambiente (as quais deveriam ser implementadas em uma base voluntária)". Além do mais, o conceito de "multifuncionalidade" passou a integrar a formulação e implementação da PAC (Fouilleux,2003:258). Este conceito passou a definir a atividade agrícola como se constituindo de duas dimensões: a produtiva e a não-comercial. Esta última abrangeria o desenvolvimento da cultura local, a defesa do meio ambiente e a manutenção do contexto social em que se desenrola a produção.

Em 2002 a Cúpula de Bruxelas aprovou a extensão das normas da PAC aos futuros membros da UE. Somado a isto, definiu-se um teto para a expansão do seu orçamento, o qual deveria vigorar até 2013.

A reforma de Meio Período da PAC foi aprovada pelo Conselho da Agricultura da UE em 26 de junho de 2003. Esta reforma representou um passo importante no sentido da redução dos subsídios à exportação, já que ela determinou, pela primeira vez e de forma definitiva, a dissociação entre produção e pagamentos aos produtores, bem como um cronograma para implementála. A reforma vinculou, ainda, o pagamento anual do produtor ao atendimento de padróes de segurança alimentar, saúde animal e defesa do meio ambiente. Outras medidas significativas incluíram a redução dos pagamentos diretos aos grandes produtores para fortalecer a política de desenvolvimento rural e a criação de mecanismos que possibilitassem à Comissão intervir caso o orçamento aprovado para a PAC até 2013 fosse excedido (Jank, 2003).

Porém, esta reforma conteve também várias qualificaçōes resultantes da pressão dos países mais protecionistas sob a liderança da França, o maior produtor agrícola do grupo, que diminuíram bastante o seu impacto. ${ }^{8}$ Dessa forma, permitiu-se aos Estados-membro manter um vínculo, ainda que limitado, entre pagamentos diretos e produção e conservarem o sistema de subsídios para determinados produtos como cereais e carne bovina. Ainda que o pagamento único passasse a ser válido a partir de 2005, fixou-se um período de transição de dois anos para que os Estados-membro se adaptassem às novas regras. ${ }^{?}$

\footnotetext{
8 "Europeus mudam política de subsídios agrícolas", O Estado de São Paulo, 27.6.2003, http://www.oesp.com.br . Visitada em 10.11.2003.

9 European Commission, CAP reform - a long-term perspective for sustainable agriculture, http://europa.eu.int/comm./agriculture/capreform/index_en.htm. Visitada em 13.11.2003.
} 


\section{A União Européia na Rodada Uruguai e Doha}

A investigação das negociações durante as Rodadas Uruguai e Doha possibilita demonstrar que os constrangimentos e políticos da UE colaboram para aumentar a capacidade deste ator em resistir às pressóes internacionais e obter resultados que se aproximaram mais de suas posiçôes relativamente à de seus contendores.

A Rodada Uruguai (1986-1994) iniciou-se com a proposta americana de eliminação de todos os subsídios agrícolas que distorcessem o comércio, proposta esta extremamente radical e a qual não foi nem endossada pelo Grupo de Cairns. Posteriormente, acordou-se que seriam transacionadas "reduçôes progressivas e substanciais no apoio à produção doméstica e subsídios" (Abreu, 1997:335).

Em 90, em Bruxelas, "na reunião que deveria coroar os quatro anos de negociações da Rodada Uruguai" a distância entre as posições americanas e da CE se mantiveram: os EUA propuseram $75 \%$ de corte no apoio doméstico e 90\% de corte de subsídios de exportação, ambos em dez anos, enquanto a CE ofereceu 30\% de cortes nos dois casos, ano base 1986 (id.ibid., 335-336).

O impasse entre a tímida proposta da CE diante da expectativa dos EUA e dos membros do Grupo de Cairns conduziu ao fracasso da Reunião de Bruxelas. Com o objetivo de impedir que a Rodada finalizasse sem os interesses pró-liberalização do mercado agrícola, o Grupo de Cairns, com a significativa atuação do Brasil e o apoio dos EUA, conseguiu a aprovação no encontro de Bruxelas da suspensão das negociações nos outros temas enquanto não se resolvesse o impasse na agricultura (Mello, 1997).

A reforma da PAC, baseada em uma revisão da proposta MacSharry e adotada pelo Conselho Europeu em maio de 1992, ainda que tenha sido limitada em relação aos seus propósitos originais, "ressuscitou a emperrada Rodada Uruguai” (Dinan, 1994:444). Contudo, a partir daí, as margens para negociação passaram a ficar condicionadas pelo que tinha sido acordado no âmbito daquela reforma.

O Relatório Dunkel, apresentado pelo diretor-geral do Gatt, em final de 91, estabeleceu aproximou as posições negociadoras com vistas a desbloquear a Rodada . Sob o ponto de vista da Comissão, com o apoio da Alemanha, interessada em abrir mercados para os seus produtos industriais, e também da Inglaterra o relatório Dunkel “(...) proporcionava uma base para o acordo final” (White, 2001:65). Porém, a França se opôs a ele e acusou a Comissão de exceder o seu mandato.

O acordo de Blair House selado entre os EUA e a CE, em novembro de 92, intensificou a oposição francesa, que sob a expectativa de uma eleição presidencial em 2003, ameaçou vetar o acordo caso ele fosse apresentado no CAG. 
Naquele acordo ficou estabelecido: $20 \%$ de redução no apoio doméstico em termos de $\mathrm{AMS}^{10}$ para o período $86-88 ; 21 \%$ de redução no volume dos subsídios exportados e $36 \%$ na redução nos valores exportados, com o período base como definido no Relatório Dunkel. (Trebilcock e Howse, 1999: 261). Além disso, os pagamentos diretos aos agricultores, com algumas ressalvas, não ficaram submetidos aos limites determinados para a redução do apoio doméstico - o que não estava claro no Relatório Dunkel e relevante reivindicação da CE já que se referia a um elemento central da reforma da PAC de 92. Houve, ainda, "uma tendência à concentração da liberalização nos produtos mais atingidos pela reforma da PAC: grãos e sementes seriam relativamente mais atingidos, carne apenas moderadamente e açúcar e laticínios quase nada"(Abreu, 1997:342). Por último, mas não menos importante, incluiu-se no acordo a Cláusula da Paz que instituía restrições à aplicação de medidas compensatórias para os países que, apesar de subsidiar as exportações e manter medidas de apoio interno com impacto negativo sobre o comércio internacional, estivessem cumprindo o que tinha sido deliberado na Rodada.

A oposição da França foi contornada com dois movimentos durante os últimos momentos do processo negociador. O primeiro, ocorreu em final de 93, em Bruxelas, quando CE e os EUA concordaram em modificar a base de cálculo para redução dos subsídios para a exportação de 86-90 para 91-92 e em estender o período de vigência da "Cláusula da Paz" de seis para nove anos. O segundo, foi uma concessão crucial de último minuto pelos Estados Unidos que atendeu a demanda da França em manter o setor cultural excluído de obrigaçōes no Acordo de Serviços (White, 2001:68).

Este relato da Rodada Uruguai demonstra a contribuição das regras institucionais e da presença da PAC para reduzir o espaço negociador da Comunidade e aumentar o seu poder de barganha. $\mathrm{O}$ resultado das negociaçóes beneficiou claramente a Comunidade e aproximou-se de suas propostas iniciais. A dinâmica entre a Comissão e o Conselho evidenciouou, também, que a capacidade de introduzir mudanças mais significativas na política agrícola é restringida pela atuação dos Estados cujos interesses estão mais próximas do status quo.

As transações que se desenrolaram no âmbito da Rodada Doha do Desenvolvimento até a VI Ministerial da OMC em Hong Kong obedeceram a um padrão semelhante ao que aconteceu na Rodada Uruguai: os resultados das negociações aproximaram-se mais das posições defendidas pela $\mathrm{CE}$ do que das posturas dos EUA, do Grupo de Cairns e do G-20, a reforma de Meio Período da PAC contribuiu para flexibilizar a posição da CE ao mesmo tempo

${ }^{10}$ Aggregate Measure of Support. O AMS é uma fórmula que permite calcular medidas domésticas de apoio ao preço a partir da relação entre um preço externo fixo de referência, o mais alto preço doméstico administrado e o volume exportado de acordo com este preço ( Trebilcock e Howse, 1999: 263). 
que passou a determinar os parâmetros do processo negociador, e a França, mais uma vez, desempenhou, com o apoio de outros países-membro, o papel de hard-liner.

Na IV Conferência Ministerial em dezembro de 2001, constituída com o propósito de decidir a agenda da nova Rodada, a CE conseguiu que as suas propostas na área agrícola fossem aprovadas pelo EUA e pelo Grupo de Cairns, ainda que com qualificações. Diversamente dos Estados Unidos e do Grupo de Cairns que demandavam a eliminação completa dos subsídios à exportação e defendendo, desde a fracassada III Ministerial em Seattle, o conceito de que a agricultura tem características específicas que a diferem de outras formas de produção e que, por conseguinte, preocupações sociais, culturais e ambientais devem ser levadas em conta nas negociações sobre a agricultura, a UE chegou a Doha com uma disposição bastante limitada de transação na área agrícola.

As suas propostas estavam calcadas em decisões tomadas anteriormente em diversos níveis decisórios da $\mathrm{CE}$ bem como nas propostas da PAC consubstanciadas na Agenda 2000. Desta maneira, a reforma da PAC aprovada pelo Conselho Europeu em Berlim em 1999 manteve os subsídios a exportação, ainda que tenha ampliado as áreas em que os produtores poderiam receber pagamentos diretos para compensar a redução nos preços, e introduziu como elemento relevante para se considerar nas decisões a respeito da atividade agrícola o conceito de multifuncionalidade.

Não estando preparada, naquele momento, para se comprometer com a eliminação dos subsídios à exportação a CE dificultou bastante o término do processo negociador se opondo ao uso da expressão "phasing out" (eliminação progressiva) em relação à redução de todas as formas de subsídios à exportação, "alegando que esta fórmula prejulgava o resultado das negociações, e poderia inclusive ser interpretada como eliminação de todos os subsídios durante a fase de implementação da Rodada" (Amorim e Thorstensen, 2002:67). A sua concordância em conservar aquele termo no texto Declaração Final ocorreu só após a introdução da frase "without prejudging the outcome of the negotiations".

Em vista disso, os resultados das negociações em Doha mantiveram na agenda os subsídios à exportação, com a aprovação da uma redução progressiva dos mesmos sem no entanto o estabelecimento de prazos. Além do mais, o documento final da Rodada incluiu de modo inequívoco que "preocupações não-comerciais serão levadas em consideração nas negociações como previsto no Acordo sobre Agricultura"11, apesar de não ter contemplado a demanda da CE, do Japão e de outros países de que constituíssem "um novo 'pilar' das negociações" (Id.ibid.).

Uma análise do processo negociador que precedeu a VI Ministerial em Hong Kong, por sua vez, bem como os resultados finais desta reunião demonstra

${ }^{11}$ Doha Ministerial Declaration, Agriculture. http://www.wto.org,. Visitada em 12.2.2005. 
a influência dos Estados-membro hard-liners e o papel que a Reforma de Meio Período de 2003 teve no sentido de condicionar a posição da UE.

Cabe destacar, contudo, que um novo elemento veio se juntar a esse quadro. Ele disse respeito ao pouco empenho demonstrado pelos Estados Unidos em avançar nas propostas de diminuição das políticas de apoio doméstico, entre eles os pagamentos contra-cíclicos, ${ }^{12}$ em decorrência da aprovação do Farm Security and Rural Investment Act em 2002 e que elevou os subsídios domésticos americanos em US\$ 75 milhões para os próximos dez anos. ${ }^{13}$ Em conseqüência, a posição dos EUA neste quesito foi defensiva e suas propostas ficaram aquém das propostas européias. Neste pilar das negociações sobre agricultura, é o ambiente interno americano que está reduzindo a ambição das transações na área, tema este relevante, mas que foge ao escopo deste artigo.

Um outro dado dessas negociaçōes é que ele se faz em um contexto de atuação expressiva do G-20 sob a liderança do Brasil e da Índia. Instituído às vésperas da $\mathrm{V}$ Ministerial em Cancún, o G-20 surgiu como resposta à tentativa de "bilateralização" das negociações ${ }^{14}$ ensaiada pelos EUA e a UE ao apresentarem uma proposta conjunta sobre agricultura que diminuía em muito à ambição do mandato da Rodada Doha. Pretendia-se repetir, com essa atuação, a experiência do Acordo de Blair House que possibilitara concluir a Rodada Uruguai, mas que, paralelamente, eliminara a participação dos países em desenvolvimento no processo negociador. O desempenho dos EUA e da UE resultou em muita insatisfação e crítica por parte dos países em desenvolvimento (Trebilcock e Howse, 1999:262). Em vista disso, cabe assinalar que o G-20 foi responsável por dar uma nova dinâmica às negociações multilaterais de comércio na OMC, inserindo nelas um significativo terceiro pólo.

A proposta americana apresentada em 10 de outubro de 2005 à OMC incluiu entre outras coisas, a eliminação total dos subsídios à exportação a partir de 2010; um corte em 60\% no apoio aos preços domésticos, exigindo um corte para UE e Japão na faixa de $83 \%$; e uma redução média de $75 \%$ nas tarifas agrícolas, incluindo a redução de $90 \%$ nas tarifas mais altas.

A reposta da UE apresentada em 28 de outubro foi bem menos ambiciosa em relação à eliminação dos subsídios à exportação e a acesso à mercados do que a dos EUA. Dessa maneira, ainda que concordasse com a proposta de eliminar os subsídios à exportação, colocou como objeto de negociação a data em que isto deveria ocorrer, sujeita a movimentos semelhantes das outras

\footnotetext{
12 Pagamentos feitos aos produtores em períodos de preços baixos no mercado internacional. A UE tem demandado a redução ou eliminação desse tipo de apoio doméstico utilizados pelos EUA.

13 Geoffrey S.Becker and Charles E. Hanrahan. Agriculture and Fast Track or Trade Promotion Authority, 2002. http://fpc.state.gov/documents/organization/16806.pdf . Visitada em 10.02.2005.

14 "O Grupo nasceu com o objetivo de tentar, como de fato o fez, impedir um resultado predeterminado em Cancun e de abrir espaço para as negociaçōes em agricultura." http://www.g-20.mre.gov.br/ history_port.asp. Visitada em 14.02.2006.
} 
contrapartes. O corte proposto nas tarifas agrícolas foi de $46 \%$, sendo a mais alta diminuída em $60 \%$.

Contudo, em relação ao pilar apoio doméstico a UE propôs a redução de $70 \%$ em subsídios agrícolas que distorcessem o comércio. A proposta de 70\% foi compatível com a soma das reduções da reforma da Política Agrícola Comum de 2003 da UE". ${ }^{15}$

A proposta da UE, por sua vez, foi acompanhada de vários desdobramentos, descritos no início deste artigo, quando a França acusou Peter Mandelson de ter excedido o mandado negociador e ameaçou vetar um possível acordo se ela implicasse em uma nova reforma da PAC.

A posição do G-20 aproximou-se da dos EUA no que concernia a eliminação total dos subsídios à exportação a partir de 2010 e acercou-se da UE relativamente à redução dos subsídios domésticos. O G-20 defendeu a diminuição de $80 \%$ nos subsídios americanos e $75 \%$ nos da UE. Em relação a acesso a mercado, o G-20 propôs um corte em média de $54 \%$ para os países desenvolvidos. ${ }^{16}$

Não foi possível se chegar a alguma decisão em relação aos dois pilares, acesso a mercado e subsídios domésticos, em função das discordâncias entre os três atores. Concordou-se, no entanto, com a eliminação total dos subsídios à exportação em 2013, data final de vigência da reforma de Meio Período da PAC de 2003, quando ela, então, deverá passar por uma nova avaliação.

\section{Conclusão}

O objetivo deste trabalho foi o de analisar a influência das instituições políticas e da PAC sobre o comportamento da UE nas negociações comerciais internacionais no âmbito da agricultura. Buscou-se demonstrar que as normas que regulam a tomada de decisão na política externa de comércio possibilitam aos Estados-membro, detentores de uma posição mais próxima ao status quo, usarem do poder de veto para obter uma ingerência significativa no processo negociador. Além do mais, investigou-se o quanto a PAC está enraizada nas estruturas políticas e sociais da UE e o quanto tem sido difícil modificá-la em um sentido mais liberalizante e competitivo, dada à oposição dos Estados mais protecionistas.

Os dois elementos - as regras e a política agrícola - aumentam o poder de barganha da UE nas transaçôes internacionais que envolvem agricultura e tornam mais difícil para os adversários obterem concessōes significativas desse

15 EU response in Doha Round found lacking, 14.11.2005, http://.un.org/special-rep/ohrlls/Hongkong/ News/14\%20Nov-1.htm. Visitada em 12.3.2006.

16 G-20 Proposal on Market Access e G-20 Proposal on Domestic Support, http://www.g-20.mre.gov.br/ proposals.asp, Visitada em 30.3.2006. 
ator no processo negociador. A averiguação do comportamento da UE na Rodada Doha e Uruguai corroborou o argumento, pois evidenciou que os resultados alcançados nessas duas rodadas se aproximaram, em larga medida, das posturas defendidas pela UE vis à vis às posições de seus opositores.

Sob o ponto de vista teórico, esta pesquisa baseia-se no quadro de referência dos Jogos de Dois Níveis sugerido por Robert Putnam (1993). O autor argumenta que, paradoxalmente, quanto menor o win-set de um negociador, isto é, quanto mais reduzido é o conjunto de alternativas ratificáveis em seu ambiente doméstico que o ator negociador pode apresentar no nível internacional, maior capacidade ele possui de conseguir um resultado na mesa de negociação que se aproxime mais diretamente de seus interesses, (id.ibid., 441-442). Esta hipótese, como salienta Putnam, calca-se, por sua vez, na abordagem proposta por Thomas Schelling (1960). De acordo com o autor, "(...) o poder de um negociador frequentemente está em uma manifesta inabilidade em fazer concessões e aprovar demandas" (id.ibid: 19). Comentando sobre a autoridade negociadora americana em acordos comerciais - o instituto da Autoridade de Promoção Comercial - Schelling afirma: “(...) se o Executivo negocia sob autoridade legislativa, com sua posição constrangida pela lei (...), então o executivo tem uma posição que é visível para seus parceiros negociadores" (id.ibid:28).

Contudo, Putnam também argumenta que movimentos no nível internacional são capazes de interferir no ambiente doméstico do ator negociador e flexibilizá-lo, aumentando assim as chances para que os opositores possam extrair dele concessões mais expressivas (Putnam, 1993 :455-456).

No caso específico da UE é preciso considerar além do nível internacional das negociações e das articulações que se desenvolvem no ambiente doméstico dos Estados, um terceiro nível, o Comunitário, "no qual os Estados-membro tentam alcançar objetivos domésticos enquanto simultaneamente perseguem uma cooperação integrativa" (Patterson, 1997: 141).

Durante as Rodadas Uruguai e Doha foram muito importantes os movimentos que ocorreram no nível internacional e que tiveram efeitos no nível Comunitário e doméstico dos países membros. Aquelas pressões conduziram a duas relevantes reformas da PAC - ainda que não tenham sido os únicos fatores responsáveis por elas - e que desbloquearam o processo negociador. Neste contexto, vale destacar o desempenho do G-20 como um elemento fundamental no conjunto de pressóes que interferiram sobre o comportamento da UE.

Por último, é preciso fazer dois comentários sobre os resultados alcançados neste artigo. Em primeiro lugar, a dinâmica de uma negociação como a que está ocorrendo na Rodada Doha implica que a restrição no âmbito da agricultura tem efeitos negativos na capacidade da UE de extrair concessões em outras áreas em negociação como, por exemplo, acesso a mercado em serviços e 
indústria. Em outras palavras, aquilo que é um trunfo em uma área de negociação pode se transformar em um impedimento em outras.

Nessa situação, além de pressões internacionais se exercerem sobre o âmbito Comunitário, outros tipos de pressões também ocorrem: a dos setores internos dos Estados-membro sobre os seus representantes políticos, já que estão interessados em obter maior acesso em serviços e produtos industriais. Em consequiência, o processo negociador no âmbito da UE torna-se mais intrincado o que pode possibilitar a realização de diferentes tipos de estratégias por parte de seus adversários.

Em segundo lugar, vale ressaltar que sob o ponto de vista da UE os constrangimentos colocados para sua atuação, e que se referem à realidade de suas instituiçōes e da sua política agrária, dificultam processos de mudança que podem ser mais interessantes sob o ponto de vista dos interesses mais gerais da UE, e que podem ser provocados pelas transações que se desenrolam ao nível internacional. Em outras palavras, a possibilidade de que acordos internacionais possam desencadear mudanças internas positivas é limitada pelo contexto restritivo ratificador. Sob o ponto de vista dos opositores, os impedimentos apresentados pela UE nas negociações agrícolas representam um desafio de formulação de estratégia negociadora, onde a atuação em múltiplos tabuleiros - no contexto internacional, bem como na esfera de relacionamento com os governos dos países membros e com seus ambientes domésticos - pode vir a desempenhar um papel fundamental.

Recebido em 1 de maio de 2006 Aprovado em 22 de setembro de 2006

\section{Referências bibliográficas}

ABREU, Marcelo de Paiva. O Brasil na Rodada Uruguai do Gatt: 1982-1993. Gelson Fonseca Júnior e Sérgio Henrique Nabuco de Castro (orgs.), Temas de Política Externa Brasileira II. Brasília, FUNAG, Rio de Janeiro: Paz e Terra, 1997, 2a ed.

ABREU, Marcelo de Paiva. O Brasil, o Gatt e a OMC: História e Perspectivas. Política Externa, vol. 9, n. 4, 2001, p. 89-119.

AMORIM, Celso e THORSTENSEN, Vera. Uma Avaliação Preliminar da Conferência de Doha - as Ambigüidades Construtivas da Agenda do Desenvolvimento. Política Externa, vol. 10, n. 4, 2002, p. 57-81.

DINAN, D. Ever Closer Union? London: Macmillan, 1994.

EPSTEIN, Paul J. Beyond Policy Community: French Agriculture and the Gatt. Journal of European Public Policy, vol. 4, n. 3, 1997, p. 355-72.

FOUILLEUX, Eve. The Common Agricultural Policy. Michelle Cini (org.), European Union Politics. Oxford: Oxford University Press, 2003, p. 247-263. 
GOLDSTEIN, Judith. Creating the Gatt Rules: Politics, Institutions and American Policy. John Ruggie (org.), Multilateralism Matters: The Theory and Praxis of an Institutional Form. New York: Columbia University Press, 1993.

KAY, Adrian. The Reform of the Common Agricultural Policy: the Case of the MacSharry Reforms. New York: CABI Publishing, 1998.

KEELER, John T. S. Agricultural Power in the European Community: Explaining the Fate of CAP and Gatt Negotiations. Comparative Politics, Vol. 28, n. 2, 1996, p. 127-149.

LANDAU, Alice. The Agricultural Negotiations in the WTO: The Same Old Story?, Journal of Common Market Studies, vol. 39, n. 5, 2001, p. 913-925.

MELLO, Flávia de Campos. O Brasil e o Gatt: Análise da Posição Brasileira nas Negociações Comerciais Multilaterais. Rio de Janeiro: Dissertação de Mestrado, Instituto de Relações Internacionais - PUC-Rio, 1997.

MEUNIER, Sophie, What Single Voice? European Institutions and EU-U.S. Trade Negotiations. International Organization, vol. 51, n. 1, 2000, p. 103-135.

MEUNIER, Sophie e NICOLAIDIS, Kalypso. Who Speaks for Europe? The Delegation of Trade Authority in the EU. Journal of Common Market Studies, vol. 37, n. 3, 1999 , p. 477-501.

PATTERSON, Lee Ann. Agricultural Policy Reform in the European Community: a ThreeLevel Game Analysis. International organization, vol. 51, n. 1, 1997, p. 133-165.

PUTNAM, Robert D. Diplomacy and Domestic Politics: The Logic of Two-Level Games. In: Peter B. Evans, Harold K. Jacobson, Robert Putnam. Double-Edged Diplomacy: International Bargaining and Domestic Politics. Berkeley: University of California Press, 1993, p. 431-468.

RIEGER, Elmar. The Common Agricultural Policy: Politics Against Markets. In: H. Wallace and W. Wallace (orgs), Policy-Making in the European Union. Oxford: Oxford University Press, 2000, 4a ed., p. 179-210.

SCHELLING, Thomas C. The Strategy of Conflict. Oxford: Oxford University Press, 1969.

SMITH, Karen E. EU External Relations. In: Michele Cini, European Union Politics. Oxford, Oxford University Press, 2003, p. 229-245.

TREBILCOCK, Michael J. e HOWSE, Robert. The Regulation of International Trade. London: Routledge, 1999, 2a Ed.

TSEBELIS, George. Veto Players: How Political Institutions Work. Princeton: Princeton University Press, 2002.

WHITE, Brian. Understanding European Foreign Policy, New York: Palgrave, 2001.

WOOLCOCK, Stephen e HODGES, M. EU Policy in the Uruguay Round. In: H. Wallace and W. Wallace (orgs.) Policy-Making in the European Union. Oxford: Oxford University Press ,1996,. $3^{\text {rd }}$ ed., p. 301-24.

WOOLCOCK, Stephen. European Trade Policy: Global Pressures and Domestic Constraints. In: H. Wallace and W. Wallace (orgs.) Policy-Making in the European Union. Oxford: Oxford University Press, 2000, 4 ed., p. 373-400.

YANK, Marcus. A Reforma da Politica Agricola Comum da União Européia, http:// www.iconebrasil.org.br/Documentos, 2003, visitada em 11.12.2004. 


\section{Resumo}

Neste artigo se analisa a influência das instituições políticas e da Política Agrícola Comum sobre o comportamento da UE nas negociações internacionais no âmbito da agricultura. Procura-se demonstrar que aqueles fatores colaboram para tornar o ambiente ratificador da UE limitado, aumentando o seu poder de barganha e reduzindo a margem de manobra dos adversários. A pesquisa enfoca, dessa maneira, o modo como os interesses dos Estados-membro são canalizados pelas instituições, bem como o desempenho da UE em relação ao comportamento dos EUA e do Brasil nas Rodadas Uruguai e Doha. .

\section{Abstract}

This article analyses the influence of political institutions and of the Common Agricultural Policy on the EU's behavior in international agricultural negotiations. It aims at demonstrating that those factors contribute to make the EU's ratification context restricted, increasing its bargaining power and reducing the leverage of its opponents. Therefore, this paper considers how the member states' interests are channeled by the institutions and the role of the EU in relation to the behavior of the USA and of Brazil in the Uruguay and Doha Rounds.

Palavras-chave: Negociação multilateral de comércio, processo decisório em política externa, União Européia.

Key words: Trade multilateral negotiations, decision making process in foreign policy, European Union. 